\title{
Maternal serum zinc deficiency in cases of neural tube defect in Gorgan, north Islamic Republic of Iran
}

\author{
M.J. Golalipour, ${ }^{1}$ M.A. Vakili, ${ }^{2}$ A.R. Mansourian ${ }^{3}$ and E. Mobasheri1
}

$$
\begin{aligned}
& \text { عوز الزنك في أمصال الأمهات في حالات عيوب الأنبوب العصبي، في جرجان في شمال جمهورية إيران الإسلامية }
\end{aligned}
$$

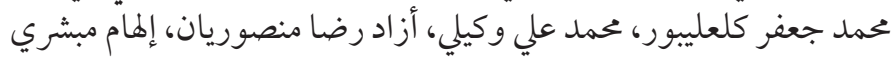

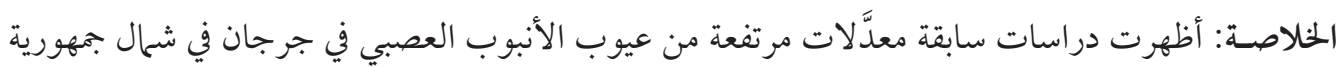

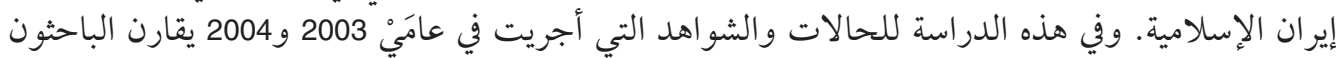

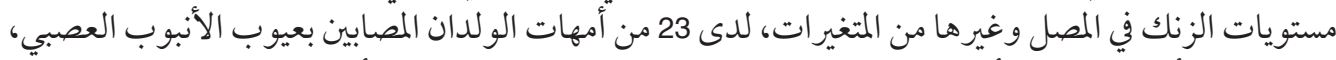

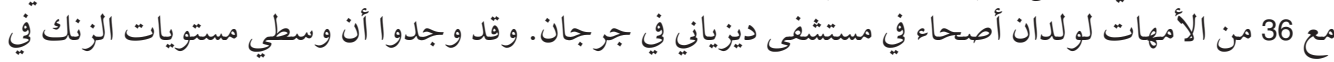

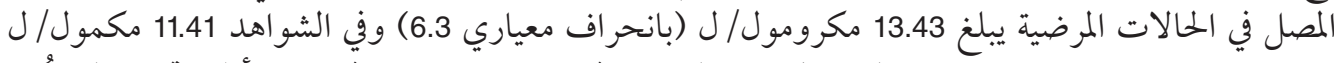

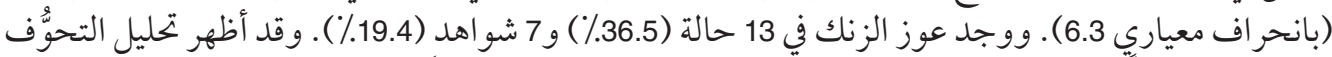

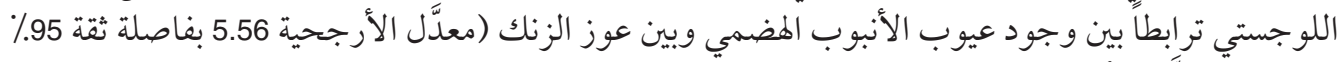

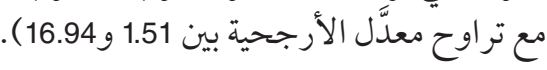

ABSTRACT Previous studies have shown a high rate of neural tube defects (NTD) in Gorgan, northern Islamic Republic of Iran. This case-control study during 2003-04 compared serum zinc levels and other variables in 23 mothers of neonates affected with NTD and 36 mothers with normal healthy neonates in Dezyani hospital in Gorgan. Mean serum zinc levels in the case and control groups were $13.43 \mu \mathrm{mol} / \mathrm{L}$ (SD 6.3) and $11.41 \mu \mathrm{mol} / \mathrm{L}$ (SD 6.3) respectively. Zinc deficiency was found in 13 (36.5\%) of the cases and $7(19.4 \%)$ of the controls. Logistic regression analysis showed an association between the presence of NTD and zinc deficiency (OR 5.06; 95\% Cl: 1.51-16.94).

Diminution du zinc sérique chez la mère et anomalies du tube neural à Gorgan (nord de la République islamique d'Iran)

RÉSUMÉ De précédentes études ont montré un taux élevé d'anomalies du tube neural (ATN) à Gorgan (nord de la République islamique d'Iran). Cette étude cas-témoins réalisée en 2003-2004 a comparé les niveaux de zinc sérique et d'autres variables chez 23 mères de nouveau-nés présentant des ATN et chez 36 mères ayant donné naissance à des enfants en bonne santé à l'hôpital Dezyani de Gorgan. Les taux moyens de zinc sérique dans le premier et le deuxième groupe étaient respectivement de $13,43 \mu \mathrm{mol} / \mathrm{L}$ (E.T. 6,3) et de 11,41 $\mu \mathrm{mol} / \mathrm{L}$ (E.T. 6,3). Une carence en zinc a été constatée chez 13 mères (36,5\%) dont le nouveau-né souffrait d'ATN et chez 7 mères $(19,4 \%)$ appartenant au groupe témoin. L'analyse de régression logistique a montré un lien entre la présence d'ATN et la carence en zinc (OR 5,06 ; IC $95 \%$ : 1,51-16,94).

${ }^{1}$ Gorgan Congenital Malformations Research Centre; ${ }^{2}$ Department of Health; ${ }^{3}$ Department of Biochemistry, Gorgan University of Medical Sciences, Gorgan, Islamic Republic of Iran (Correspondence to M.J.

Golalipour: mjgolalipour@yahoo.com).

Received: 25/05/06; accepted: 06/11/06

المجلة الصحية لشرق المتوسط، منظمة الصحة العالمية، المجلد الخامس عشر، العدد Y، 9 +. 


\section{Introduction}

Neural tube defects (NTD) are severe congenital malformations which occur due to abnormalities in neural tube formation [1]. They include spina bifida, anencephaly and encephalocele and are an important cause of perinatal morbidity and mortality [2]. NTD are the second cause of serious congenital malformations in the United States of America after heart malformation [3].

The incidence of NTD varies by geographical zone [4]. The spectrum is wide, ranging from 1 per 100 live births in parts of China to about 1 per 5000 live births in Scandinavian countries [4]. In many countries the prevalence is approximately 1 per 1000 births. In recent years some studies have shown the prevalence of NTD ranging from 1.76 to 5.1 per 1000 in some parts of the Islamic Republic of Iran [5-7]. Furthermore, 2 previous studies reported the prevalence of NTD at 2.88 per 1000 and 3.12 per 1000 in Gorgan in the north of the country $[8,9]$.

The etiology of these anomalies is not completely understood and has often been considered multifactorial, with genetic and environmental as well as nutritional factors playing a role [10-12]. Nutritional factors such as folic acid and zinc deficiency are believed to be important in NTD [13]. Zinc is a trace element required by the organism for multiple biological functions, including cell division, development and differentiation. Zinc is a cofactor for many enzymes in various metabolic pathways, for example in nucleic acid synthesis [13-15]. Studies carried out in different parts of the world have shown the role of zinc deficiency in NTD [14-18].

Faced with a high prevalence of NTD in our region $[8,9]$, we planned this study to determine the role of maternal serum zinc deficiency in NTD in neonates.

\section{Methods}

\section{Setting}

This case-control study was conducted at Dezyani hospital, the main referral hospital with a labour facility in Gorgan, the capital of Golestan province in the north of the Islamic Republic of Iran. The hospital handles more than 6000 deliveries per annum, accounting for the majority of deliveries $(70 \%)$ in the city. Patients are usually from moderate to low socioeconomic classes.

\section{Sample}

To estimate the zinc level in mothers of neonates with NTD and healthy mothers with a probability of $95 \%$ and power of $80 \%$, sample size was estimated to be $\geq 21$ for each group. The case group comprised all 23 mothers who gave birth to babies with NTD during the study period (June 2003 to September 2004). For the control group, for every case we selected the subsequent 2 mothers who gave birth to normal, healthy babies. As some of the blood samples haemolysed and some control mothers did not agree to enter the study, the final sample for the control group was 36 .

\section{Data collection}

All babies delivered in this hospital during the investigation period were examined after delivery for NTD by a gynaecologist and later the diagnosis was confirmed by a paediatrician. The health of neonates in the control group was assessed clinically by a gynaecologist and paediatrician before these mothers entered the study. A questionnaire covering all relevant clinical and demographic factors was filled out for each case and control infant by the paediatrician and then completed by a nurse during an interview with the mothers. The data included: birth date, sex, birth weight, birth height, gestational age and type of 
NTD. Also recorded were: parents' ages, mother's parity, mother's previous history of abortions, family history of congenital anomalies and mother's history of exposure to any type of drugs during the 1 st trimester of pregnancy (except for folate, which is routinely give to pregnant women).

A peripheral blood sample was collected from all mothers and the serum samples were analysed for zinc level by spectrophotometric methods (Randox kit, UK). Zinc deficiency was defined as a zinc level $<10.6 \mu \mathrm{mol} / \mathrm{L}[19,20]$.

Ethical consent was obtained for the study from the ethical committee of Gorgan University of Medical Sciences. The mothers' consent was obtained prior to their entering the study.

\section{Analysis}

Student $t$-test, chi-squared, Mann-Whitney and Fisher exact tests were performed for statistical analysis. Odds ratios (OR) and 95\% confidence interval (CI) were calculated as part of logistic regression analysis using SPSS, version 11.5, in a saturated model using forward stepwise procedures modelling according to the likelihood ratio.

\section{Results}

We studied 23 mothers with neonates affected with NTD. Age range for the case mothers was 21-42 years and for the case fathers 22-42 years. The most frequent type of NTD was spina bifida in 14 neonates (61\%), followed by anencephaly in $7(30 \%)$ and encephalocele in $2(9 \%)$. The control group was 36 healthy mothers with normal babies. The ages range of the mothers of the controls was 17-37 years and for the control fathers $20-0$ years.

Multiparty (4+ pregnancies) was reported in $17.4 \%$ of the case mothers and $16.7 \%$ of the control mothers. No risk tendency for NTD was found to be related to number of pregnancies $\left(\chi^{2}=0.016, P=\right.$ 0.493 ). A past history of infants with NTD was not reported by any mother in either group. However, mother's history of congenital malformations other than NTD was reported by $11.1 \%$ of the cases and $4.3 \%$ of the controls (Table 1).

No statistically significant differences were found between the groups for any of the demographic or family history variables (Table 1).

The mean gestational age for the cases was 36.39 weeks [standard deviation (SD) 2.35], range 31-38 weeks, and for controls 38.53 weeks (SD 0.81), range 36-39 weeks $(P=0.001)$ (Table 2).

The mean serum zinc level in mothers of NTD neonates [11.41 $\mu \mathrm{mol} / \mathrm{L}$ (SD 6.3 ), range 2.2-35.4] was lower than in the control group [13.43 $\mu \mathrm{mol} / \mathrm{L}$ (SD 6.3) range

Table 1 Demographic characteristics of mothers with neonates affected by neural tube defects (NTDs) and healthy controls

\begin{tabular}{lccc}
\hline Variable & Cases $(\boldsymbol{n}=\mathbf{2 3})$ & Controls $(\boldsymbol{n}=\mathbf{3 6})$ & $\boldsymbol{P}$-value \\
\hline Maternal age [mean (SD) years] & $26.9(6.1)$ & $25.6(5.3)$ & $0.38^{\mathrm{a}}$ \\
Paternal age [mean (SD) years] & $30.1(6.1)$ & $29.0(6.1)$ & $0.33^{\mathrm{a}}$ \\
Multiparity [no. (\%)] & $4(17.4)$ & $6(16.7)$ & $0.48^{\mathrm{b}}$ \\
Previous abortion [no. (\%)] & $5(13.9)$ & $3(13.0)$ & $0.62^{\mathrm{b}}$ \\
History of births with NTD [no. (\%)] & $0(0.0)$ & $0(0.0)$ & - \\
History of births with other congenital & & & \\
malformations [no. (\%)] & $4(11.1)$ & & \\
\hline
\end{tabular}

a Student t-test; ${ }^{b}$ Chi-squared test.

المجلة الصحية لشرق المتوسط، منظمة الصحة العالمية، المجلد الخامس عشر، العدد Y، 9. ب. 
Table 2 Birth and gestational characteristics of neonates affected by neural tube defects and healthy controls

\begin{tabular}{lccc}
\hline Variable & Cases $(\boldsymbol{n}=\mathbf{2 3})$ & Controls $(\boldsymbol{n}=\mathbf{3 6})$ & $\boldsymbol{P}$-value \\
\hline Birth weight [mean (SD) g] & $2910(726)$ & $3460(490)$ & $0.001^{\mathrm{a}}$ \\
Birth height [mean (SD) cm] & $46.4(4.75)$ & $49.7(2.50)$ & $0.006^{\mathrm{a}}$ \\
Gestational age [mean (SD) weeks] & $36.39(2.35)$ & $38.53(0.81)$ & $0.001^{\mathrm{b}}$ \\
Maternal exposure to drugs in 1st & & & \\
trimester [no. (\%)] & $6(26.1)$ & $1(2.8)$ & $0.011^{\mathrm{c}}$ \\
Low maternal serum zinc levele [no (\%)] & $13(56.5)$ & $7(19.4)$ & $0.003^{\mathrm{d}}$ \\
\hline
\end{tabular}

${ }^{a}$ Student t-test; ${ }^{b}$ Mann-Whitney test; ${ }^{\circ}$ Fisher exact test; ${ }^{d}$ Chi-squared test; ${ }^{\circ}<10.6 \mu \mathrm{mol} / \mathrm{L}$.

6.2-38.2], but not statistically significantly so $(P=0.092)$. Significantly more of the cases $(n=13,56.5 \%)$ than the controls had zinc deficiency $(n=7,19.4 \%)$ (serum zinc $<10.6 \mu \mathrm{mol} / \mathrm{L})(P=0.003)($ Table 2$)$.

Medications consumed during pregnancy in the case group were antibiotics and analgesics for urinary tract infections (4), propranolol for bicuspid valve prolapse (1) and anti-hyperthyroid drugs (1) (Table $2)$. In the control group 1 mother had been exposed to antibiotics. This difference was significant $(P=0.007)$.

Logistic regression analysis of the significant variables showed an association between the presence of NTD and zinc deficiency (OR 5.06; 95\% CI: 1.51-16.94; $P=0.008)$ and drug consumption during the 1st trimester (OR 13.12; 95\% CI: $1.31-$ 130.97; $P=0.028$ ) (Table 3).

\section{Discussion}

The results of this study indicated that there was an association between NTD in neonates and zinc deficiency in mothers. Our findings are similar to results from research in Canada [15], France [21], California [14] the Netherlands [22] and elsewhere [23-25]. Our findings are also comparable with studies in neighbouring Turkey. In a case-control study, Cengiz et al. found that serum zinc levels in mothers with NTD were significantly lower than in controls [26]. Cavdar et al. showed that maternal serum and hair zinc concentrations in the NTD group were lower than those in the control group [16]. Other researchers, however, reported no relation between zinc deficiency and NTD [27-30]. One study showed a significant relation between maternal nutrition during pregnancy and NTD [31].

The diversity of functions in the organism has yielded diverse hypotheses to explain the association between zinc deficiency and NTD. Abnormal synthesis of nucleic acids and proteins, abnormal polymerization of tubulin, chromosome defects, excessive cell death and an increase in cell membrane lipid peroxidation in humans may be due to zinc deficiency [32]. A promising finding for the prevention of NTD has been the discovery of the protective effect of

\begin{tabular}{|c|c|c|c|}
\hline \multicolumn{4}{|c|}{$\begin{array}{l}\text { Table } 3 \text { Logistic regression analysis of the } \\
\text { variables included in the study }\end{array}$} \\
\hline Risk factor & $\begin{array}{l}\text { Adjusted } \\
\text { OR }\end{array}$ & $95 \% \mathrm{Cl}$ & $P$-value \\
\hline $\begin{array}{l}\text { Low maternal } \\
\text { serum zinc } \\
\text { level }\end{array}$ & 5.06 & $1.51-16.94$ & 0.008 \\
\hline $\begin{array}{l}\text { Maternal } \\
\text { exposure } \\
\text { to drugs in } \\
\text { 1st trimester }\end{array}$ & 13.12 & $1.31-130.97$ & 0.028 \\
\hline
\end{tabular}


folic acid [33-37], leading to recommendations for folate supplementation in the diet of pregnant women. It has been noted that the periconceptional use of folate supplements also reduced the incidence of NTD [38]. In a systematic review of case-control studies, a moderate association between low maternal vitamin B12 status and the risk of fetal NTD was noted [39].

Although folic acid supplementation programmes have been implemented for pregnant women in many countries, NTD continue to be one of the most frequent congenital malformations worldwide. This directed us to presume that not all NTDs are related to folic acid, and that other genetic and nutritional factors may play an important role. According to the MRC Vitamin Study Research Group report, only $70 \%$ of NTDs were prevented by supplemental folic acid, and that zinc deficiency could also play a role $[14,15,23,40,41]$.

Recently, Velie et al. studied the periconceptional use of vitamins, minerals and food supplements in mothers of 430 babies with NTD and 429 controls. They found a protective effect of zinc on NTD [14]. Folic acid and zinc deficiencies have been proposed elsewhere as possible causes of NTD [42]. Therefore administration of zinc during pregnancy is at least as important as folic acid [43]. An American study showed that higher preconceptional intake of nutrient zinc decreased the risk of NTD [23].

Other studies have also indicated a moderate association between low maternal B12 status and the risk of fetal NTD $[39,44]$. Afman et al. suggested that vitamin B12 supplementation might therefore be warranted for prevention of NTD [44].

Genetic factors have also been hypothesized. Some researchers in the Eastern Mediterranean Region have reported that consanguinity in parents of babies with NTD is high $[45,46]$.
The other significant difference between the cases and controls in the present study was the consumption of medications in the 1 st trimester of pregnancy, a factor that is widely accepted as a cause in congenital malformations. A study in Turkey reported a significant relation between medication during pregnancy and NTD [31]. We also observed a shorter gestational time in cases than in controls and a lower weight and length in cases that were probably a result of the congenital malformations.

\section{Conclusion}

In this study, the first of its kind in this region, we found an association between NTD and low zinc levels, adding to the evidence about the importance of nutritional and maternal health factors in the etiology of this disease. In addition to folic acid supplementation, zinc supplementation should be considered for the further decrease in the recurrence and occurrence of NTD.

In our opinion, it would be better to select the study group at 12-16 weeks of pregnancy after the diagnosis of NTD in the fetus with ultrasonography because the zinc concentration in mothers could change during the next 2 trimesters. Further studies in humans are needed to clarify the metabolic interrelations between folic acid and zinc to provide more solid support for supplementation programmes during gestation.

\section{Acknowledgements}

The authors wish to thank the Research Deputy of Gorgon University of Medical Sciences for financial support, the Dezyani hospital director and the neonatal ward staff, especially Dr Mirfazeli (neonatalogist), Mrs Hajizade and Miss Soraya Ghafari for their assistance in this project. 


\section{References}

1. Copp AJ et al. The embryonic development of mammalian neural tube defects. Progress in neurobiology, 1990, 35(5):363-403.

2. Lary JM, Edmonds LD. Prevalence of spina bifida at birth-United States, 19831990: a comparison of two surveillance systems. Morbidity and mortality weekly report, 1996, 45(2):15-26.

3. Lynberg MC, Khoury MJ. Contribution of birth defects to infant mortality among racial/ethnic minority groups, United States, 1983. Reports on selected racial/ethnic groups; special focus: maternal and child health. Morbidity and mortality weekly report, 1990, 39(SS-3):1-12.

4. Botto LD, Yang Q. 5,10-Methylenetetrahydrofolate reductase gene variants and congenital anomalies: a HuGE review. American journal of epidemiology, 2000, 151(9):862-77.

5. Farhud DD, Valizadeh GR, Kamali MS. Congenital malformations and genetic diseases in Iranian infants. Human genetics, 1986, 74:382-5.

6. Farhud DD, Hadavi V, Sadighi H. Epidemiology of neural tube defects in the world and Iran. Iranian journal of public health, 2000, 29:1-4.

7. Afshar M, Golalipour MJ, Farhud D. Epidemiologic aspects of neural tube defects in South East of Iran. Neurosciences, 2006, 11(4):447-50.

8. Golalipour MJ, Vakili MA, Arya B. Neural tube defects in newborns in the southeast of the Caspian sea border [Gorgan, Iran 1998-2000]. Medical journal of the Islamic Republic of Iran, 2003, 16:199203.

9. Golalipour MJ et al. North of Iran 19982003: epidemiology of neural tube defects. Eastern Mediterranean health journal, 2007, 13(3):560-6.
10. Seller MJ. Risks in spina bifida. Developmental medicine and child neurology, 1994, 36(11):1021-5.

11. Van Loon K, Besseghir K, Eshkol A. Neural tube defects after infertility treatment: a review. Fertility and sterility, 1992, 58(5):875-84.

12. Harris MJ, Juriloff DM. Mini-review: towards understanding mechanisms of genetic neural tube defects in mice. Teratology, 1999, 60(5):292-305.

13. Milunsky A et al. Maternal zinc and fetal neural tube defects. Teratology, 1992, 46(4):341-8.

14. Velie EM et al. Maternal supplemental and dietary zinc intake and the occurrence of neural tube defects in California. American journal of epidemiology, 1999, 150(6):605-16.

15. Buamah PK et al. Maternal zinc status: a determination of central nervous system malformation. British journal of obstetrics and gynaecology, 1984, 91(8):788-90.

16. Cavdar AO et al. Zinc status in pregnancy and the occurrence of anencephaly in Turkey. Journal of trace elements and electrolytes in health and disease, 1988, 2(1):9-14.

17. Bergmann KE, Makosch G, Tews KH. Abnormalities of hair zinc concentration in mothers of newborn infants with spina bifida. American journal of clinical nutrition, 1980, 33(10):2145-50.

18. Carrillo-Ponce ML et al. Serum lead, cadmium, and zinc levels in newborns with neural tube defects from a polluted zone in Mexico. Reproductive toxicology, 2004, 19(2):149-54.

19. Makino T et al. A highly sensitive colorimetric determination of serum zinc using water-soluble pyridylazo dye. Clinica chimica acta, 1982, 120(1):127-35. 
20. Homsher R, Zak B. Spectrophotometric investigation of sensitive complexing agents for the determination of zinc in serum. Clinical chemistry, 1985, 31(8):1310-3.

21. Favier $M$ et al. La carence en zinc chez la mére peut-elle étre responsable de l'apparition de spina bifida aperta chez le foetus? [Can zinc deficiency in the mother be responsible for the occurrence of spina bifida aperta in the fetus?] Revue francaise de gynecologie et d'obstetrique, 1987, 82(10):575-81.

22. Groenen PM et al. Maternal myo-inositol, glucose, and zinc status is associated with the risk of offspring with spina bifida. American journal of obstetrics and gynecology, 2003, 189(6):1713-9.

23. Shaw GM et al. Periconceptional nutrient intake and risk for neural tube defect-affected pregnancies. Epidemiology, 1999, 10(6):711-6.

24. Groenen PM et al. Are myo-inositol, glucose and zinc concentrations in amniotic fluid of fetuses with spina bifida different from controls? Early human development, 2003, 71(1):1-8.

25. Cavdar AO et al. Zinc deficiency and anencephaly in Turkey. Teratology, 1980, 22(1):141-4.

26. Cengiz B et al. Serum zinc, selenium, copper, and lead levels in women with second-trimester induced abortion resulting from neural tube defects: a preliminary study. Biological trace element research, 2004, 97(3):225-35.

27. Hambidge M, Hackshaw A, Wald N. Neural tube defects and serum zinc. British journal of obstetrics and gynaecology, 1993, 100(8):746-9.

28. Nikolov V, Tsachev K, Marinov B. Kontsentratsiia na tsink $v$ maichin serum i okoloplodna technost pri bremennosti s nevralni defekti na ploda vuv vtori trimestur [The zinc concentration of the maternal serum and the amniotic fluid in pregnancies with fetal neural defects in the second trimester]. Akusherstvo i ginekologiia, 1993, 32(2):8-10.

29. Weekes EW et al. Nutrient levels in amniotic fluid from women with normal and neural tube defect pregnancies. Biology of the neonate, 1992, 61(4):226-31.

30. Ghosh A et al. Zinc deficiency is not a cause for abortion, congenital abnormality and small-for-gestational age infant in Chinese women. British journal of obstetrics and gynaecology, 1985, 92(9):886-91.

31. Mandiracioglu A et al. The incidence and risk of neural tube defects in Izmir, Turkey: a nested case-control study. Turkish journal of pediatrics, 2004, 46:214-20.

32. King JC. Determinants of maternal zinc status during pregnancy. American journal of clinical nutrition, 2000, 71(5 Suppl.):1334S-43S.

33. Rieder MJ. Prevention of neural tube defects with periconceptional folic acid. Clinics in perinatology, 1994, 21(3):483-503.

34. Shaw GM et al. Maternal vitamin use, genetic variation of infant methylenetetrahydrofolate reductase, and risk for spina bifida. American journal of epidemiology, 1998, 148(10):30-7.

35. Centers for Disease Control and Prevention. Recommendations for use of folic acid to reduce number of spina bifida cases and other neural tube defects. Journal of the American Medical Association, 1993, 269(10):1233:6-8.

36. Prevention of neural tube defects: results of the Medical Research Council Vitamin Study. MRC Vitamin Study Research Group. Lancet, 1991, 338:131-7.

37. Prevention of neural tube defects: integrated management of pregnancy and childbirth (IMPAC). Department of making pregnancy safer. Geneva, World Health Organization, 2006. 
38. Lumley $\mathrm{J}$ et al. Periconception supplementation with folate and/or multivitamins to prevent neural tube defects (Cochrane review). In: The Cochrane library, Issue 4. Chichester, John Wiley and Sons, 2001.

39. Ray JG, Blom HJ. Vitamin B12 insufficiency and the risk of fetal neural tube defects. Quarterly journal of medicine, 2003, 96:289-95.

40. Rosado JL. Deficiencia de zinc y sus implicaciones funcionales [Zinc deficiency and its functional implications]. Salud pública de México, 1998, 40(2):181-8.

41. Hinks LJ et al. Maternal zinc and selenium status in pregnancies with a neural tube defect or elevated plasma alphafetoprotein. British journal of obstetrics and gynaecology, 1989, 96(1):61-6.

42. Cloherty JP, Stark A, Eichenwald E, eds. Manual of neonatal care. Philadephia, Lippincott Williams and Wilkins, 1998.
43. Cavdar AO et al. Effect of zinc supplementation in a Turkish woman with two previous anencephalic infants. Gynecologic and obstetric investigation, 1991, 32(2):123-5.

44. Afman LA et al. Reduced vitamin B12 binding by transcobalamin II increases the risk of neural tube defects. Quarterly journal of medicine, 2001, 94:159-66.

45. Aqrabawi HE. Incidence of neural tube defects among neonates at King Hussein Medical Centre, Jordan. Eastern Mediterranean health journal, 2005, 11(4):81923.

46. Murshid WR. Spinabifida in Saudi Arabia: is consanguinity among the parents a risk factor? Pediatrics neurosurgery, 2000, 32(1):10-2.

\section{Correction}

Epidemiological transition of some diseases in Oman: a situational analysis. S.S. Ganguly, M.A. Al-Shafaee, J.A. Al-Lawati, P.K. Dutta1 and K.K. Duttagupta. Eastern Mediterranean health journal, 2009, 15(1):209-18.

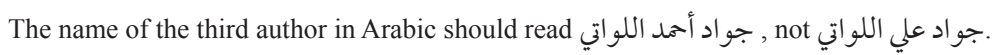

